\section{Acidentes e sua prevenção}

\section{Work accidents and their prevention}

Ildeberto Muniz de Almeida

José Marçal Jackson Filho
Este número da Revista Brasileira de Saúde Ocupacional (RBSO) é dedicado a estudos sobre acidentes do trabalho e aspectos afins da segurança do trabalho.

Ao longo das últimas décadas, cresceu entre nós o número de estudiosos que exploram o tema dos acidentes do trabalho. Boa parte de seus estudos $^{1}$ pode ser encontrada em sítios da internet que, embora de acesso gratuito, não parecem ter sido descobertos pelos profissionais de segurança que atuam em empresas, instituições e organismos externos às universidades e instituições de pesquisa. Três aspectos nos parecem relacionados com o crescimento desse tipo de estudos.

O primeiro é o movimento realizado no âmbito de universidades brasileiras em busca do aprimoramento da qualidade de sua produção científica, incluindo exigência de titulação de seu corpo docente, com aumento do intercâmbio com instituições de outros países e a abertura de cursos de pós-graduação que passam a desenvolver colaboração com empresas, organismos governamentais, e serviços especializados que atuam nos campos da segurança e da saúde do trabalhador, criando oportunidades para aumento: a) da difusão de novas formas de pensar a segurança, o risco e a prevenção; b) do diálogo entre pesquisadores e interessados de diferentes áreas afins ao estudo de acidentes; e c) do desenvolvimento de estudos centrados em múltiplos aspectos dos acidentes.

O segundo, menos evidente, parece associado com o crescimento da oferta de serviços ditos de saúde do trabalhador em, praticamente, todos os estados do país. A procura de profissionais desses serviços por cursos de pós-graduação em áreas afins à saúde do trabalhador parece fenômeno estabelecido entre nós e diretamente relacionado com o aumento da produção acima referida. Alguns poucos serviços já realizam movimento visando à sua própria constituição e reconhecimento como centro de pesquisa e produção de conhecimento.

O terceiro aspecto situa-se no mundo do trabalho propriamente dito e nas transformações por que tem passado nosso país com reflexos nas áreas de segurança e saúde no trabalho na esfera governamental e também em centros de pesquisa. Nas últimas décadas, é crescente o número de sistemas para os quais a ocorrência de acidentes, desastres ambientais, eventos de grande impacto e incômodo social e político assumiram destaque de preocupação estratégica.

Esse movimento não só incentiva o surgimento de questionamentos no interior desses sistemas acerca dos limites da abordagem tradicional de acidentes, como também a busca de novos caminhos, seja na direção de novas roupagens a serem assumidas pelas abordagens que insistem em explicar os acidentes como eventos decorrentes de comportamentos faltosos de trabalhadores descritos como elos fracos dos sistemas, seja na busca de maior aproximação com explicações centradas em enfoques sistêmico, sociotécnico ou psico-organizacional. Esse último caminho tende a aumentar a aproximação entre esses sistemas e as universidades e centros de pesquisa ${ }^{2}$ existentes no país.

\footnotetext{
1 Está fora do objetivo desta apresentação a indicação de lista da produção científica brasileira deste período. No entanto, os interessados no tema não podem deixar de acessar o endereço www.scielo.br e pesquisar com uso de expressões como acidente do trabalho, acidentes maiores ou ampliados, erro humano, investigação de acidentes, segurança do trabalho, prevenção de acidentes ou assemelhadas. Também é possível fazer busca com o nome de autores de seu interesse.
}

\footnotetext{
${ }^{2}$ Correndo o risco de cometer injustiças, é possível afirmar que já temos número importante de bons estudos sobre acidentes oriundos de serviços e profissionais com formação em Epidemiologia, Ergonomia - Engenharia de Produção, Saúde do Trabalhador, Saúde Pública / Saúde Coletiva, Ciências Sociais, Psicologia Social, dentre outras. Felizmente, já é possível identificar exemplos desses profissionais e estudos em muitos estados do país, embora o maior número ainda se concentre em São Paulo, Rio de Janeiro, Minas Gerais, Rio Grande do Sul e Bahia.
} 
${ }^{3} \mathrm{O}$ que explica a dificuldade dos especialistas da segurança de compreenderem a realidade do trabalho e sua complexidade (ver, por exemplo, JACKSON \& AMORIM, 2001; LIMA, 2002).

${ }^{4} \mathrm{Em} 2004$, no Brasil, houve mais de 371 mil acidentes do trabalho típicos e 2801 óbitos (BRASIL, 2007).

${ }^{5}$ Aliás, mecanismos com a finalidade de alocação da culpa já são conhecidos há algum tempo nas Ciências Sociais (DOUGLAS, 1985).

${ }^{6}$ Que inclusive fundamenta a prática profissional da Engenharia de Segurança por meio de norma da ABNT de 2001.
Enfim, é possível afirmar que o chamado desafio da gestão de segurança em sociedade dinâmica mostra reflexos também entre nós (RASMUSSEN, 1997). No entanto, é preciso destacar que esse movimento ainda está longe de derrotar e substituir o paradigma tradicional que permanece hegemônico no país, inclusive na maior parte do aparelho formador que oferece cursos de especialização em Engenharia de Segurança ${ }^{3}$, Medicina do Trabalho, Enfermagem do Trabalho ou de formação de técnicos de segurança do trabalho.

Além disso, é preciso destacar que resistências às novas abordagens também aparecem na forma de obstáculos ao livre acesso a informações, ao desenvolvimento de diálogo com pesquisadores e à abertura de portas para pesquisas coordenadas por setores independentes a esses sistemas e, enfim, ao estabelecimento de mecanismos democráticos de controle social de sistemas cujo funcionamento implica em riscos à saúde de populações de usuários, mas não só, e também em possíveis impactos adversos ao meio ambiente.

\section{A necessidade da construção de um novo olhar para estudos de acidentes: desafio para a prevenção}

De um lado, o grande número de acidentes do trabalho é grave problema social em nosso país ${ }^{4}$. De outro, os estudiosos do tema no Brasil e no mundo têm criticado fortemente as conclusões de várias análises de acidentes conduzidas no âmbito de empresas e de algumas instâncias governamentais e as concepções teóricas e metodológicas que lhes dão suporte.

Sem pretender esgotar a amplitude dessas críticas, vale lembrar que, entre outros, elas destacam os seguintes aspectos: o número médio de fatores apontados como envolvidos nas origens de acidentes é muito pequeno. Na maioria das situações, os fatores identificados como mais importantes nas conclusões dessas "análises" se referem a comportamentos de trabalhadores, em especial, ações ou omissões situadas pouco antes do desfecho do acidente. Esses comportamentos costumam ser descritos e discutidos com o uso de categorias como atos e condições (ambientes) inseguros ou fora de padrão, falhas humanas ou técnicas ou outras abordagens de formato dicotômico que adotam como pressuposto a idéia de existência de um jeito certo, ou seguro, de realizar aquela ação que seria previamente conhecido do operador envolvido e que, na situação do acidente, teria deixado de ser usado como resultado de uma escolha consciente, originada em aspectos do próprio indivíduo, quiçá, de sua personalidade descuidada, indisciplinada ou equivalente.

De acordo com essas conclusões, esses acidentes também são vistos como fenômenos individuais ou, no máximo, restritos a um dos componentes do sistema sociotécnico aberto envolvido na atividade que era desenvolvida. Esse componente é o alvo das recomendações de prevenção. Compreendida como um sistema, a organização em que se dá esse evento é diagnosticada como sem problemas. $\mathrm{O}$ acidente deixa de ser compreendido como sinal de disfunção sistêmica ou como revelador, seja de situações com potencial acidentogênico, seja como fonte de aprendizado organizacional e caminhos para aperfeiçoamento desse sistema (CTL, 1991; LLORY, 1999a, 1999b; REASON, 1997; REASON \& HOBBS, 2003; WOODS \& COOK, 2002).

Essa forma de conceber o acidente como fenômeno simples foi chamada de abordagem ou paradigma tradicional por diversos autores (CATTINO, 2002; LLORY, 1999b; DWYER, 2000).

Infelizmente, enquanto o usuário desse modelo de investigação vê a conclusão centrada em aspectos do componente ou fator humano como mero produto de um trabalho técnico, no mundo real, esses resultados acabam alimentando práticas de atribuição de culpa típicas da abordagem tradicional de acidentes (VILELA et al., 2004), como temos visto nas declarações de algumas autoridades da área e deputados da CPI criada para investigar a crise do setor aéreo no país. ${ }^{5}$

Apesar da relativa difusão alcançada pela crítica a esse olhar tradicional ${ }^{6}$, os interessados na utilização de novas ferramentas disponibilizadas para a análise de acidentes, seja no campo do ensino, seja no terreno das práticas desenvolvidas em instituições governamentais e empresas, ainda encontram dificuldades no acesso a publicações construídas com base nesse novo olhar sobre falhas, erros e segurança. 


\section{Novas concepções para a compreensão dos acidentes}

Na literatura internacional, acidentes como o do vôo 1907, mas não só, suscitam estudos que exploram diferentes aspectos. De forma didática, recorrendo a Llory (1999b) é possível recomendar a divisão do acidente em três períodos e distribuir os estudos segundo o tipo de aspectos que exploram como relacionados aos períodos: a) pós-acidental; b) acidental ou do acidente propriamente dito; e c) pré-acidental.

O período pós-acidente já foi denominado como período de crise social em casos de dimensões catastróficas, em que a situação é vista como ameaça à forma e à estrutura do sistema. Se existem, as estruturas sociais são incapazes de resolver os problemas econômicos, sociais, culturais e políticos evidenciados no pós-acidente e ameaçam a integridade do sistema (SHRIVASTAVA, 1987). Entre estudos relativos a esse período, podemos citar aqueles que exploram conseqüências psíquicas e sociais de acidentes, seja para as próprias vítimas, seja para seus familiares; ou os que exploram a resposta de emergência tanto no que se refere à interrupção do processo acidental em si, como na minimização de seus impactos ambientais, danos materiais e custo humano. Há ainda estudos que exploram custos financeiros, descrição de recursos mobilizados na assistência de saúde, efeitos tardios, de instalação crônica ou que atingem descendentes das populações atingidas no acidente, como nos casos de contaminação química ou radioativa etc.

Os estudos relacionados a aspectos dos períodos chamados de acidente propriamente dito e pré-acidental são aqui abordados rapidamente e de modo conjunto. Entre eles estão incluídos aqueles que detalham aspectos técnicos do processo de descontrole ou liberação de fluxo de energia envolvido no acidente. Atualmente, há maior divulgação de abordagens sustentadas na noção de modelo de acidente que usam princípios como os de análise de barreiras e análise de mudanças na descrição desses eventos e recomendam a continuidade dessa análise no período pré-acidental, evitando interrupções precoces da busca de aspectos que participam do acidente (ALMEIDA, 2006; HOLLNAGEL, 2004; KLETZ, 2006).

Outros estudos apontam para a contribuição de propriedades de sistemas, como a complexidade interativa e a convivência com situações de incerteza nas origens de acidentes (PERROW, 1999). Também há autores que lidam com a relação entre projeto (design) de subsistemas técnicos e a segurança ou, ainda, aqueles que exploram comportamentos humanos nessas situações, procurando descrever aspectos dos modos de gestão psíquica/cognitiva e mobilizações afetivas presentes na atividade e rompidos pelo acidente (AMALBERTI, 1996).

Nos primórdios da introdução desse tipo de estudo, estão as abordagens que exploram isoladamente os componentes humano, técnico e operacional dos sistemas sociotécnicos em questão. Em seguida, sob a influência de ergonomistas e psicólogos cognitivistas, surgem críticas à idéia de que a confiabilidade humana seja uma propriedade invariável do ser humano. Ela passa a ser estudada como "propriedade do funcionamento humano dentro de determinadas condições, para um determinado tipo de tarefa” (LEPLAT, 2006, p. 27). Daí a preferência pela expressão componente humano da confiabilidade.

Esses pesquisadores enfatizam a necessidade de conhecer o trabalho real com ênfase em aspectos de sua variabilidade e nas estratégias usadas no cotidiano pelos operadores para resolver problemas, superar dificuldades e manter o funcionamento do sistema. De modo assemelhado, para Rasmussen (1997), a análise do trabalho real mostra a variedade das situações vividas pelos operadores e não previstas nas normas de segurança vigentes, assim como as tentativas de desenvolvimento de modos operatórios que reduzam os custos humanos e aumentem a eficiência do trabalho. As ações desenvolvidas para gerir a variabilidade do trabalho são descritas por Rasmussen como adaptações locais. Elas podem resolver ou não o problema enfrentado. Muitas vezes, nessas situações, os operadores precisam fazer escolhas entre, de um lado, ações que visam retomar a produção, porém contrariam normas de segurança, e, de outro, ações que privilegiam a segurança e implicam em atraso na retomada dos trabalhos. 
Essas adaptações locais implicam em tomadas de decisão e adoção de práticas que tanto podem criar riscos como segurança. Por isso, risco e segurança podem se constituir como propriedades emergentes de sistemas.

Segundo Neboit (2003), nessas situações, o trabalhador lida com uma abordagem de risco e perigo diferente daquela tradicional centrada na idéia de liberação de fluxo de energia a ser controlado. Nessa segunda abordagem, o operador é ator de interações numa situação que, na gestão de riscos, privilegia o papel do seu conhecimento sobre o trabalho real e sua utilização na compreensão da atividade que desempenha no sistema.

Relatando discussão sobre vazamento de substância inflamável desencadeado por tentativa de correção autorizada por supervisor, Kletz (2006) destaca:

[o ...] supervisor não atuava no vácuo. Seu julgamento foi influenciado por sua avaliação sobre as reações de seus chefes e pela atitude em relação à segurança na companhia, como demonstrado pelas ações realizadas ou observações feitas em outras situações. Declarações sobre políticas oficiais têm pouca influência. Nós julgamos as pessoas pelo que elas fazem, não pelo que elas dizem. O gerente da fábrica tem grande carga de responsabilidade no estabelecimento de um clima [...] em que seu staff sente que correr risco é legítimo. (p. 73)

Outros estudos enfatizam as relações sociais estabelecidas nas instituições, por exemplo, sistemas de recompensas e práticas de controles como origens socialmente construídas de erros que levam a acidentes (DWYER, 2007). Sob essa ótica, os acidentes são "construtos sociais" (WOODING \& LEVEINSTEIN, 1999; MACHADO et al., 2000).

No conjunto de estudos citados, os comportamentos humanos no trabalho passam a ser vistos de modo absolutamente distinto daquele que predomina na abordagem tradicional.

Por sua vez, o enfoque clássico ressurge em estudos que reiteram a importância de erros humanos como principais "causas" dos acidentes e defendem a adoção de estratégias de segurança comportamental como caminho a ser seguido pelos interessados na gestão de segurança. A busca desse objetivo seria baseada em recenseamentos de "atos inseguros" que ensejariam intervenções de devoluções individuais ou coletivas direcionadas à redução de comportamentos indesejados. Entre os adeptos deste enfoque também se defende a criação de uma cultura de segurança, entendida como equivalente da soma de comportamentos (seguros) dos integrantes do sistema como estratégia central para a gestão de segurança.

Esse é, talvez, o mais controverso dos múltiplos sentidos atribuídos à expressão cultura de segurança. No âmbito deste texto, fica registrada a crítica ao reducionismo dessa visão e à necessidade de explicitação do seu sentido quando a expressão é utilizada.

A construção de uma cultura de segurança também é defendida por Reason (2000). Ele destaca três aspectos que caracterizariam sua existência: a) uma cultura de informação, ou seja, a existência de atmosfera de confiança que permita a implementação de sistema de informações de eventos adversos e memória do sistema; b) uma cultura de justiça, ou seja, ambiente de acordo e compreensão sobre atos passíveis e não passíveis de culpa; e por fim c) uma cultura de aprendizagem caracterizada pela existência de medidas reativas e pró-ativas usadas para criar melhorias contínuas do sistema. Mais recentemente, há esboço de diálogo entre essa forma de pensar a cultura de segurança e abordagens originadas das correntes das organizações de alta confiabilidade, da ergonomia da atividade e da psicologia cognitiva (REASON, 2000; BOURRIER, 2001).

Esses tipos de estudos apontam a importância da alta hierarquia nos esforços de modificação de aspectos das diversas subculturas de segurança existentes no sistema e minimizam a importância das conclusões de análises que atribuem o acidente a falhas de trabalhadores.

Em março de 2007, nos Estados Unidos, o Chemical Safety Board (CSB) publicou sua conclusão sobre a análise de acidente que destruiu a planta da Formosa Plastics: "A companhia e seu proprietário anterior não planejaram adequadamente como lidar com os erros humanos” (CSB, 2007). A página do CSB apresenta outros exemplos de relatórios com conclusões assemelhadas. Até o momento do fechamento deste número 
da RBSO, os autores não tinham notícias da existência, entre nós, de análise de acidentes com esse tipo de conclusões.

\section{A colisão entre os aviões Gol-Legacy: fatos e reflexões}

O texto da chamada de artigos para este número da Revista Brasileira de Saúde Ocupacional (RBSO) citava os acidentes do Fokker 100, da plataforma P-36 e da base de Alcântara como exemplos de ocorrências que desafiavam os interessados na prevenção.

Infelizmente, entre o lançamento daquela chamada e o fechamento da Revista, o país foi abalado por novos acidentes que, no mínimo, não só atestam a atualidade do desafio destacado naquele texto, como produziram novos exemplos de manifestações públicas típicas da busca de bodes expiatórios e do reducionismo presentes nas abordagens tradicionais de acidentes. Vários exemplos poderiam ser citados, mas pelo encaminhamento recentemente assumido, inclusive com abertura de Comissão Parlamentar de Inquérito (CPI), a colisão no ar do avião da Gol (vôo 1907) e do jato Legacy, ocorrida em outubro de 2006, assumiu lugar emblemático.

Neste texto, aspectos da dimensão pública assumida por esse caso ensejam comentários que procuram ilustrar críticas ao chamado paradigma tradicional de modo a mostrar possibilidades de interpretações alternativas aos "fatos" citados e dar exemplos dos conceitos que vêm sendo usados nesse tipo de situações já há alguns anos, embora ainda pouco difundidos entre nós.

No caso da aviação, há anos se utiliza concepção e modelo de análise que explora separadamente fatores "humanos", "técnicos" e "operacionais"7. É a aceitação acrítica dessa abordagem fragmentada ${ }^{8}$ que leva integrantes de equipes de análise a considerarem natural conclusão de investigação centrada em falhas do "componente humano", por exemplo, de controladores de vôo ou pilotos, na análise desse acidente. Uma vez que a exploração conduzida não identifique falhas "técnicas” nem "operacionais", a conclusão enfatizando falha humana ganha força.

A cobertura da mídia sobre o acidente Gol-Legacy mostrou grande número de reportagens centradas na idéia de rápida definição de responsáveis, pilotos ou controladores, cujos erros explicariam o acontecido. Ao mesmo tempo, houve acúmulo de notícias revelando que a situação do controle aéreo no país convivia com bem conhecidos problemas crônicos, seja de atraso na reposição ou substituição de equipamentos, seja na carência de recursos humanos, seja na área de gestão do setor, ensejando sobrecarga de trabalho e lenta e progressiva degradação das condições do sistema. E isso tudo num contexto de grandes dificuldades de acesso a informações tratadas como "segredos" de estado. Algumas dessas informações são contestadas, sobretudo por autoridades da área.

Mas não foram apenas esses os problemas. É praticamente certo que, no momento do choque, o sistema anticolisão (TCAS) do Legacy não estivesse funcionando. As razões para esse fato estão sendo buscadas na investigação. Foi grande o número de referências a problemas no sistema de comunicações entre pilotos e controladores na região do acidente. Uma das principais redes de TV do país colocou no ar imagens realizadas semanas após o acidente da sala de controle aéreo que confirmariam a existência de "pontos cegos", ou áreas em que os radares deixariam de detectar a presença de aeronaves, e de imagens de naves inexistentes ("alvos falsos") nas telas de radares que cobrem a mesma região da colisão. Parte dessas informações tem sido contestada.

De acordo com a imprensa, a região do acidente, na Serra do Cachimbo, está situada no equador magnético que pode interferir nas ondas eletromagnéticas que se propagam, degradando, inclusive, os sinais transmitidos pelos satélites GPS. Isso poderia interferir nas comunicações entre controladores e tripulações e também no funcionamento de outros equipamentos necessários ao bom funcionamento do sistema de navegação aérea. Também essas informações são contestadas por autoridades da área.

Houve profusão de notícias em relação a aspectos da formação e dos comportamentos da tripulação do Legacy e também de controladores das torres de Brasília e São José dos Campos que teriam levado ao acidente. Imediatamente após o acidente, uma ex-au-
${ }^{7}$ Um dos aspectos que permite a identificação entre a abordagem tradicional e o modelo de três fatores separados usado na análise de acidentes no setor aéreo é o fato desses dois enfoques adotarem os mesmos pressupostos, ou seja, a mesma compreensão sobre o que é o ser humano e sobre comportamentos humanos no trabalho. Nos dois casos, os comportamentos dos trabalhadores continuam sendo vistos como produtos de escolhas livres e conscientes, independentemente dos demais componentes do sistema sociotécnico e do contexto em questão.

${ }^{8}$ Vale a pena registrar também o fato de que equipes de análises formadas para a utilização desses modelos de investigações nem sempre são informadas sobre os pressupostos que eles assumem e, por isso mesmo, tendem a assumilos como a única forma possível e não como escolha dentro do leque de alternativas explicitadas e comparadas. 
toridade do setor aéreo, atualmente ocupando cargo de direção da empresa fabricante de um dos aviões, afirmou que o acidente só podia ser explicado por falhas humanas.

Os registros acima mostram a persistência de opiniões que entendem como supostas causas do acidente eventos proximais ao desfecho, sobretudo comportamentos atribuídos aos controladores do Cindacta 1, de Brasília, e da tripulação do Legacy. Essa forma de ver o acidente tende a concordar com explicações que encerrem a análise sem explorar a fundo aspectos dos períodos pré-acidental e do acidente propriamente dito. Por outro lado, os fatos apontados também indicam que o funcionamento do sistema em questão é marcado por intensa e extensa troca de informações entre diferentes atores situados a centenas ou milhares de quilômetros de distância. Essas trocas são mediadas por equipamentos aparentemente sensíveis a influências diversas, inclusive do ambiente.

As notícias também indicam que pressões exercidas depois do acidente, em especial sobre controladores de vôo, estiveram associadas ao desencadeamento de reações de estresse agudo e de outras manifestações de mal-estar ou transtornos psíquicos e de comportamento entre os trabalhadores. Por sua vez, a cobertura dos trabalhos das equipes de busca e salvamento na região do acidente também mostra indícios de ausência de suporte psíquico aos militares e demais trabalhadores envolvidos em tarefa que há anos é reconhecida como de grande potencial nocivo para a saúde mental dos trabalhadores.

Mais recentemente, com a criação da Comissão Parlamentar de Inquérito (CPI) do "apagão aéreo", surgiram acusações abertas contra controladores de vôo que atuavam em Brasília no dia do acidente. No início das atividades da CPI, o seu presidente declarou sua convicção de que a responsabilidade pelo acidente era dos controladores e que um deles seria acusado de homicídio doloso. Nesse caso, uma intervenção, iniciada com gesto de oportunismo político óbvio, encontrou repercussão na mídia e, com isso, potencializou os prejuízos latentes que trazia em seu bojo.

Em entrevista a uma das principais redes de TV do país, interrogado sobre o significado que atribuía às dificuldades de comunicação com a tripulação do Legacy, um dos controladores acusados afirmou tratar-se de situação comum, que estranhara ao iniciar na atividade, mas que logo fora orientado pelos colegas mais experientes que era assim mesmo. Em síntese, disse que no dia do acidente agira da mesma maneira que estava acostumado a agir e que nunca antes houvera problema. O relato sugere ainda que essa situação era conhecida dos superiores hierárquicos.

Dias mais tarde, o Ministério Público denunciou por crime de "atentado contra segurança de vôo" os pilotos do jato Legacy e quatro controladores, sendo que um dos controladores foi denunciado por crime doloso (LOPES, 2007).

Embora a veracidade ou a eventual contribuição de alguns dos fatos citados possa ser alvo de questionamentos, as reflexões a seguir nos parecem pertinentes.

Não é difícil perceber que, nesses casos, o número de atores sociais e de recursos técnicos que interagem na operação dos sistemas em questão, por si só, já podem ser tomados como indicadores de complexidade.

A acusação formulada aos controladores de vôo é um bom exemplo de situação que explica o acidente de modo centrado no indivíduo e nos acontecimentos que antecedem imediatamente o desfecho da situação, regra geral com base na idéia de que o operador cometeu algum ato faltoso ou erro humano, identificado com uso da noção de desrespeito às regras, normas e preceitos de segurança.

Uma das primeiras críticas aos limites desse enfoque descreve os acidentes como eventos multicausais, resultados de seqüências lineares de eventos e, posteriormente, de rede de fatores em interação.

Nas últimas décadas, é crescente o número de estudos que mostram que as origens dos acidentes localizam-se na própria história do sistema, na interação de aspectos como decisões estratégicas, desenho e escolhas de tecnologias, definições políticas, práticas organizacionais e formas habituais de respostas a momentos de variabilidade normal e incidental da atividade desenvolvida no sistema (WISNER, 1994). De acordo com esses estudiosos, diferentemente daqueles que se referem aos operadores como 
“elos fracos”, a intervenção deles é a principal responsável pela segurança dessas organizações (DE KEISER, 2005).

Em sistemas que funcionam com recursos técnicos defasados, como parece ser o caso do nosso controle aéreo, ou melhor, de nossa segurança aérea, graças ao acúmulo de problemas instala-se, lentamente, estado ou situação de fragilização da segurança. Em outras palavras, proliferam e permanecem incubadas formas de funcionamento e condições que, apesar de isoladamente não serem facilmente reconhecidas como sinais ou avisos de perigo iminente e de não afetarem o desenvolvimento habitual das atividades, podem interagir entre si ou com fatos novos e ultrapassar as capacidades de defesa instaladas no sistema, levando a acidentes.

Esses últimos acontecimentos representam gatilhos que disparam ou desencadeiam o acidente e, com freqüência, tendem a ser considerados como causas desses eventos. Essa forma de entender o acidente e o papel desses gatilhos desconsidera que, na maioria dos casos, eles só desencadeiam o acidente na vigência da condição de fragilização historicamente construída e incubada no sistema.

É exatamente por isso que, nesses sistemas, cresce a importância da contribuição do seu componente humano, ou seja, de seus trabalhadores de todos os níveis para a segurança, uma vez que o número de situações que passam a exigir diagnóstico e correções tende a ser maior. Os ajustes realizados pelos operadores em resposta à variabilidade dos sistemas, nas diferentes condições de seu funcionamento, tendem a ser responsáveis pela sua segurança real.

O acúmulo de problemas técnicos e organizacionais capazes de interagir de múltiplas formas e contribuir para as origens de acidentes foi descrito por Reason como condições latentes. Sua mudança seria crucial para os interessados na prevenção de acidentes e muito mais importante do que aquelas dirigidas a comportamentos de trabalhadores que tenham "disparado" o acidente.

A detecção e correta interpretação de eventos (incidentes, disfuncionamentos etc.) que surgem no funcionamento dos sistemas e antecedem o acidente não são coisa fácil como costuma ser afirmado por integrantes de equipes de "investigação" que chegam aos cenários já sabendo o que aconteceu e acreditando que tudo está explicado ao evidenciar exemplo de comportamento ou acontecimento que contraria normas de segurança vigentes.

Todavia, os comportamentos humanos em situação de trabalho não se reduzem a seguir procedimentos ou normas, ao contrário, envolvem interações permanentes com recursos dos sistemas técnicos e materiais colocados à sua disposição, assim como com outros colegas e chefias num determinado ambiente e contexto organizacional. Aliás, em determinadas situações, a adoção de modo operário baseado em procedimento de segurança pode não evitar acidentes ou incidentes (DECKER, 2003).

O uso desses recursos e as trocas intersubjetivas realizadas em situação de trabalho são influenciados, entre outros, por aspectos como: os objetivos definidos pelas chefias; as releituras desses objetivos pelos próprios trabalhadores; as características da interface dos sistemas, inclusive no tocante ao feedback que oferece aos operadores de modo a favorecer ou dificultar a construção e a manutenção da compreensão sobre o desenvolvimento do trabalho; o estado de funcionamento dos sistemas técnicos. Ele também é influenciado por aspectos temporais, fisiológicos (vigília, fadiga etc.), psíquicos (cognitivos e afetivos) e da história do coletivo de trabalhadores que realiza aquele trabalho (ASSUNÇÃO \& LIMA, 2003).

Vejamos mais um exemplo:

No domingo, 18 de fevereiro de 2007, os jornais do país dedicaram longas reportagens sobre o que seria a transcrição de diálogos da caixa-preta do Legacy. Chamada de notícia da Folha de São Paulo (CANTANHÊDE, 2007) destacava que "Controladores não sabiam que aeronaves estavam na mesma altitude”. A matéria tratava de controlador de vôo que, no dia do acidente, trabalhava no Cindacta-1, de Brasília, e que em depoimento à Polícia Federal teria informado que [por ocasião do acidente] "estava ocupado "com outros tráfegos' [aviões]”. E acrescenta: 
${ }^{9}$ Por exemplo, o acidente de Three Miles Island (DANIELLOU, 1986).
O sargento não percebeu que o sistema corrigiu automaticamente o plano de vôo virtual do Legacy quando este passou por Brasília, mostrando altitudes previstas e não as que estavam efetivamente sendo voadas (CANTANHÊDE, 2007, p. C9).

Os autores não puderam checar a veracidade dessa afirmação, mas a literatura de acidentes já relata vários exemplos em que dispositivos automáticos agem de modo que tende a criar armadilha cognitiva para seus operadores ${ }^{9}$. Diante desse fato é que consideramos importante refletir sobre as questões a seguir. Será que, em condições normais, esse tipo de correção poderia influenciar a compreensão de controlador de vôo em relação à real situação do avião, levando-o a achar que ele estava na altura mostrada na tela e a não se comunicar com a tripulação de modo a checar a altura real? E se a mesma pergunta for feita em situações ou momentos de sobrecarga de trabalho? Ou em que a atenção do controlador se volta para a compreensão de dificuldades e tentativas de solucioná-las? E de pressão de tempo? E de estresse emocional? Ou, como freqüentemente se vê no cotidiano desses operadores, de somação desses tipos de eventos ou ainda a necessidade de partilhar sua atenção entre diferentes objetos? Enfim, será que esse tipo de reflexão pode ser útil às equipes de análises, inclusive em relação às demais situações de interações entre operadores e meios técnicos que utilizam?

As abordagens que se resumem à identificação e classificação de comportamentos como certos ou errados e que os entendem como produtos de escolhas conscientes dos operadores envolvidos não conseguem oferecer suporte às equipes de análise na discussão dos diversos eventos e aspectos que antecedem os acidentes. Elas tendem a ser incapazes não só de enxergar a profusão e a complexidade das interações presentes na operação desses sistemas, como de compreender o fato de que, nesses processos, o operador influencia e é influenciado pelo sistema em que está inserido, enfim, pelas relações que estabelece no seu trabalho.

Nesta breve reflexão, pretendeu-se apontar nova forma de abordar os acidentes que enfatiza a importância da análise de condições latentes nas origens de acidentes, sem descuidar da exploração de contribuições do componente humano da confiabilidade entendida no conjunto de relações estabelecidas nas situações de trabalho. Essa nova forma é usada em contraposição às versões que tentam explicar acidentes, como o da colisão dos aviões - mas não só -, como produtos isolados de falhas humanas, frutos do acaso ou eventos totalmente imprevisíveis, sem a participação de elementos incubados na história desses sistemas. Enfim, parece-nos essencial desconstruir a abordagem tradicional de acidentes, o que não é tarefa simples, pois, o senso comum, malgrado todas as evidências, tende a ressaltar o "comportamento improcedente, inadequado ou imprudente", como indica a fala contraditória do relator da CPI do "apagão aéreo": "Parece que o sistema tem falhas. Neste caso, embora o sistema seja falho, a causa do acidente foi humana." Ainda segundo ele:

\footnotetext{
Não tenho dúvidas de que J. cometeu a falha mais grave. Ficou bem evidente que, como técnico, ele falhou. Ele teve uma falha decisiva. Acho que foi negligente, imprudente e cometeu imperícia. Mas não tinha a intenção de provocar o acidente. (LOPES, 2007, p. c3)
}

Assim, no caso da colisão Gol (vôo 1907)-Legacy, o grave é que a leitura tradicional persiste e, aliada ao discurso político de ocasião, sugere desfecho em que, mais uma vez, as muitas falhas identificadas deixam de ser interpretadas como sinais de fragilidades do sistema em questão e como janelas de oportunidade para o aprendizado organizacional. Esse quadro é agravado pela falta de transparência na condução das investigações. É hora da sociedade exigir a instalação de mecanismos que aumentem as possibilidades de controle público e de democratização do setor.

\section{Apresentação dos textos}

Felizmente, como poderemos observar nos artigos que compõem esta coletânea, há indícios de que, entre nós, o tema dos acidentes de trabalho já é tratado, em vários centros, com metodologias e abordagens que podem ajudar a melhor compreender 
as causas dos acidentes e que podem contribuir para aumentar a confiabilidade e a segurança de sistemas.

Os doze artigos desta coletânea podem ser divididos em dois grupos: no primeiro, o traço comum aos oito trabalhos é a crítica ao modelo tradicional de análise de acidentes e a proposição de novas formas para abordar e compreender os acidentes; no segundo, os quatro artigos apresentados tratam de novas perspectivas e questões sobre a atuação dos agentes públicos no âmbito da saúde e da segurança dos trabalhadores.

Oliveira, ao analisar o discurso de trabalhadores em indústria metalúrgica, mostra a difusão entre os trabalhadores do discurso dominante que imputa a causa dos acidentes aos atos inseguros e para o qual os riscos fazem parte do processo de trabalho e são, portanto, "naturais". Aponta, também, para falas que propõem a ruptura e que seriam formas de resistência ao processo de culpabilização dos trabalhadores e de "naturalização dos riscos”. A difusão deste contra-discurso depende da ação conjunta de trabalhadores, sindicalistas e técnicos do campo da SST.

Vilela et al. apresentam caso de investigação e análise, realizada pelo CEREST de Piracicaba, de acidente sofrido por operador em máquina fresadora semi-automática. Contrariando os laudo feitos pelo Instituto de Criminalística (IC) e pelo Serviço Especializado de Segurança e Medicina do Trabalho (SESMT) da empresa, que apontaram a imprudência e a negligência dos operadores envolvidos como causa do acidente, os resultados da análise do CEREST evidenciaram aspectos associados à organização do trabalho, ao projeto do equipamento na origem do acidente e, sobretudo, à fragilidade conceitual que embasou os laudos do IC e do SESMT.

Câmara et al., em estudo no setor extrativista vegetal baseado em análise documental, observações e entrevistas no setor de derrubada de árvores, descrevem as atividades e o saber prático dos operadores para lidar com a variabilidade e os determinantes das situações de trabalho (externos aos trabalhadores) e para evitar os riscos presentes, contrariando a visão simplista proposta pela abordagem clássica dos acidentes, que atribui ao comportamento inseguro dos trabalhadores a causa principal dos mesmos.

Fonseca e Lima analisam o efeito da introdução de nova tecnologia na construção civil - novo tipo de escoramento de lajes - no surgimento de acidentes por quedas dos trabalhadores. Os resultados da análise ergonômica realizada mostraram que o modo de introdução da tecnologia levou a uma ruptura entre a experiência dos trabalhadores desenvolvida na situação anterior e aquela desenvolvida na nova situação de trabalho.

Strausz et al. analisam um acidente por contaminação fúngica em biblioteca pública. A aplicação da metodologia de Análise Interdisciplinar e Participativa de Acidentes (AIPA), concebida inicialmente para explicar acidentes de alta complexidade, mostrou-se eficaz, trazendo à tona os problemas gerenciais na origem do acidente e o descontrole ambiental que gerou exposições múltiplas a agentes físicos e biológicos.

Cardoso e Cukierman propõem novo entendimento para o acidente ocorrido em 1989 no vôo RG-254 baseado em enfoque sociotécnico e no conceito de "acidente normal”. Analisando as relações entre os atores-rede envolvidos no sistema de aviação em que ocorreu o acidente, mostram que ele não foi provocado por falha humana, mas pelo rompimento das relações entre os atores envolvidos.

Lima apresenta as contribuições do método da Clínica da Atividade, proposto por Yves Clot, para a compreensão de acidentes do trabalho. Para ilustrar o interesse pelo método, discute-se estudo realizado no setor petroquímico (coordenado por Ferreira), que mostrou a relação entre a gestão de pessoal da empresa, caracterizada pela diminuição dos seus efetivos e o aumento de contratos com empreiteiras, e seu funcionamento e sua segurança. Os acidentes graves ocorridos na empresa entre os anos de 2000 e 2001 podem ser explicados como decorrência da fragilização do "gênero profissional" estabelecido pelas equipes de operação e sua influência no funcionamento coletivo diante das medidas adotadas pela empresa.

Marziale et al. realizaram estudo transversal a fim de descrever os acidentes envolvendo exposição a material biológico em um hospital universitário, entre os anos 
de 2003 e 2004. Dos 107 acidentes ocorridos, a maioria envolveu mulheres com lesões perfurantes nas mãos e trabalhadores que pertenciam às unidades de clínica médica e de pronto atendimento.

Lorenço e Bertami abordam os desafios e as perspectivas atuais para o campo da saúde do trabalhador e para o Sistema Único de Saúde. A partir da análise e do relato de três situações - um acidente de trabalhador no meio rural, a sobrevivência de família que vive da coleta de lixo, o trabalho de crianças guardando carros - evidencia-se o sofrimento dos "trabalhadores" que se submetem a condições insalubres e precárias para sobreviver. Concluem que as ações e as políticas públicas devem considerar não apenas "novas", mas também velhas questões que envolvem as relações entre trabalho e saúde.

Santana et al. apresentam resultados oriundos de estudo de coorte de base comunitária sobre saúde e trabalho iniciado em 2000. Neste trabalho, caracterizam a utilização dos serviços de saúde por trabalhadores que sofreram acidentes do trabalho. Mostram que a maioria dos entrevistados foi atendida pelo SUS, independentemente de possuir plano de saúde privado ou não. As características de utilização dos serviços por trabalhadores acidentados são necessárias para potencializar as ações de prevenção pelo SUS.

Quinlan et al. apresentam e discutem esforços recentes, na Austrália e no Reino Unido, para proteger a saúde e a segurança de trabalhadores vulneráveis nas cadeias de fornecedores. As regulamentações propostas nestes países, viabilizadas pelos dispositivos gerais contidos na legislação em SST e baseados no princípio de cadeia de responsabilidades, visam combater os efeitos da precarização do trabalho em diversos setores: transporte rodoviário, construção, vestuário e produtos agrícolas.

Mendes e Wünsch refletem sobre o cenário contemporâneo das relações entre saúde e trabalho e mostram a importância de constituir nova cultura em saúde e segurança no trabalho. Para superar o que chamam de viés prevencionista - modelo hegemônico, centrado no biológico e no individuo -, alertam para a necessidade de consolidar socialmente os avanços obtidos no campo da saúde do trabalhador.

O conjunto desses textos contribui certamente para uma melhor compreensão dos acidentes do trabalho e de suas causas e, portanto, para a elaboração de ações e políticas de prevenção mais eficazes. Os textos mostram que as novas abordagens para análise das causas dos acidentes podem ser aplicadas, sendo necessárias não apenas para a compreensão de acidentes envolvendo sistemas sofisticados, mas também nas diversas situações de trabalho de diversas formas de produção. Enfim, partilham de paradigma comum, no qual homens e mulheres na produção não são o elo fraco dos sistemas de produção e o "fator de risco", ao contrário, são considerados agentes essenciais para o funcionamento seguro dos sistemas.

\section{Comentário final: a invisibilidade dos acidentes do cotidiano}

No Brasil, todos os anos, de forma silenciosa, milhares de trabalhadores morrem ou sofrem mutilações no trabalho. O impacto desses agravos que ocorrem "no varejo" é muito maior que o desses grandes acidentes, mas apesar disso permanece quase invisível para a sociedade brasileira.

Neste número da RBSO procuramos mostrar que as nossas possibilidades de aprendizado com base em análises de acidentes são ameaçadas todas as vezes que se alimenta conclusão que assume o formato de revelação da "causa" - assim mesmo, no singular - do acidente. Ou seja, aquelas que tendem a reduzir o acontecido a uma falha de componente do sistema ou, no máximo, a algumas falhas de componentes tratados como segmentos isolados ou seu mero ajuntamento. E, conseqüentemente, perde-se a oportunidade de analisar esse evento como sinal de fragilidade do subsistema de gestão de saúde e segurança do trabalho - ou por exemplo do sistema de segurança aérea nos acidentes recentes - em nosso país.

O leitor desavisado tende a prender-se na explicação simplista, em especial quando anunciada com pose doutoral ou ênfase típica de dono da verdade. O subsistema de 
gestão de saúde e segurança no trabalho (SGSST), assim como o sistema de segurança aérea do país, precisa ser entendido como o organismo sociotécnico cujo funcionamento articulado depende e é produzido por todos os seus componentes, em particular pelas interações que estabelecem, pelas funções que só desempenham quando atuam como integrantes desse sistema.

Aparentemente, intervenções, como a da CPI do apagão aéreo, representam mais um passo infeliz. Ao insistir na idéia de identificar culpado a receber punição exemplar, como no caso do controlador do Cindacta 1, elas “jogam água no moinho” da explicação simplista.

A discussão está lançada. As abordagens de acidentes apresentadas neste número da RBSO destacam a importância da identificação dos fatores sociotécnicos que desencadeiam tais eventos e, ao mesmo tempo, a necessidade de identificar as condições préexistentes no sistema sem as quais não aconteceriam. Entre nós, historicamente, essa última etapa tem sido sistematicamente obstruída e inviabilizada. Continuará tudo como dantes no reino de Abrantes?

Eventos complexos não têm respostas simples. Não há um remédio ou solução mágica para a situação da segurança no trabalho no país hoje. É hora de iniciar a caminhada necessária no rumo da construção do sistema que rompa de vez com o paradigma tradicional, com seus prejuízos em termos de inibição da prevenção, e estabeleça as bases necessárias à construção de novos olhares sobre os acidentes.

\section{Referências}

ALMEIDA, I. M. Trajetória da análise de acidentes: o paradigma tradicional e os primórdios da ampliação da análise. Interface, Botucatu, v. 10, n. 19, p. 185-202, 2006.

AMALBERTI, R. La conduite de systèmes à risques. Paris: Presses Universitaires de France, 1996.

ABNT. ASSOCIAÇÃO BRASILEIRA DE NORMAS TÉCNICAS. NBR 14280. Cadastro de acidente do trabalho: procedimento e classificação. Rio de Janeiro, 2001.

ASSUNÇÃO, A. A.; LIMA, F. P. A. A contribuição da ergonomia para a identificação, redução e eliminação da nocividade do trabalho. In: MENDES, R. Patologia do trabalho. 2. ed. atual. e ampl. São Paulo: Atheneu, 2003. v. 2, parte III, cap. 45, p. 1767-1789.

BOURRIER, M. Organiser la fiabilité. Paris: L’Harmattan, 2001.

BRASIL. Anuário Estatístico da Previdência Social - 2004. Disponível em: http://www. previdenciasocial.gov.br/aeps2004/13_01_20_01.asp. Acesso em: 24 maio 2007.

CANTANHÊDE, E. Certeza do choque dos aviões só veio após pelo menos 50 minutos. Folha de São Paulo, São Paulo, 18 fev. 2007. Caderno C, p. 9.

CATTINO, M. Da Chernobyl a Linate. Incidenti tecnologici o errori organizzative? Roma: Carocci, 2002.

CFB. CHEMICAL SAFETY BOARD. Final Report and Safety Video on Formosa Plastics Explosion in Illinois. Available in: www.csb.gov. Access: 25 apr. 2007.

CTL. COGNITIVE TECHNOLOGIES LABORATORY. A brief look at the New Look in complex systems, failure, error and safety. 2002. Available at: csel.eng.ohio-state.edu/ woods. Access: 12 dec. 2006.

DANIELLOU, F. L'opérateur, la vanne et l'écran. L'ergonomie des salles de contrôle. Montrouge: Editions de l'Anact, 1986.

DE KEISER, V. O erro humano. In: CASTILLO, J. J.; VILLENE, J. Ergonomia, conceitos e métodos. Lisboa: Dinalivro, 2005. p. 247-265.

DEKKER, S. Failure to adapt or adaptations that fail: contrasting models on procedures and safety. Appl. Ergon., v. 34, n. 3, p. 233-238, 2003.

DOUGLAS, M. Risk acceptability according to the Social Sciences. New York: Russel Sage Foundation, 1985. 
DWYER, T. A study on safety and health management at work: a multidimensional view from a developing country. In: FRICK, K. et al. Systematic occupational health and safety management. Amsterdam: Pergamon, 2000. p. 149-74.

. Vida e morte no trabalho. São Paulo: Unicamp/ Multiação, 2007.

HOLLNAGEL, E. Barriers and accident prevention. Aldershot, UK: Ashgate, 2004.

JACKSON FILHO, J. M.; AMORIM, J. L. A introdução de políticas de ergonomia na indústria: missão para os engenheiros de segurança? In: CONGRESSO LATINO AMERICANO DE ERGONOMIA - ABERGO 2001, 6., 2001, Gramado. Anais... Gramado: Abergo, 2001. CD ROM.

KLETZ, T. Accident investigation: keep asking “why?”. Journal of Hazardous Materials, v. 130, p. 69-75, 2006.

LEPLAT, J. Risque et perception du risque dans l'activité. In: KOUABENAN, D. et al. (Dir.) Psychologie du Risque. Identifier, évaluer, prévenir. Bruxelles: Éditions de Boeck, 2006. p. 19-33.

LIMA, F. A formação em Ergonomia: reflexões sobre algumas experiências de ensino da metodologia de análise ergonômica do trabalho. In: KIEFER, C.; FAGA, I.; SAMPAIO, M. R. Trabalho, saúde e educação: um mosaico em múltiplos tons. São Paulo: Fundacentro. 2001. p. 113-148.

LLORY, M. Acidentes industriais: o custo do silêncio. Rio de Janeiro: MultiMais Editorial, 1999a.

1999b.

. L'accident de la centrale nucléaire de Three Mile Island. Paris: L'Harmattan,

LOPES, E. Choque no ar: 'Confiei no sistema', diz em CPI controlador acusado por tragédia. O Estado de São Paulo, São Paulo, 29 maio 2007. Caderno C, p. 3.

MACHADO, J. M. H.; PORTO, M. F. S.; FREITAS, C. M. Perspectivas para uma Análise Interdisciplinar e Participativa (AIPA) no contexto da indústria de processo. In: FREITAS, C. M.; PORTO, M. F. S.; MACHADO, J. M. H. (Org.). Acidentes industriais ampliados: desafios e perspectivas para o controle e prevenção. Rio de Janeiro: Fiocruz, 2000.

NEBOIT, M. Abordagem dos fatores humanos na prevenção de riscos no trabalho. In: ALMEIDA, I. M. Caminhos das análises de acidentes. Brasília: Ministério do Trabalho e Emprego, 2003. p. 85-98.

PERROW, C. Normal accident. Living with high risk technologies. Princeton, New Jersey: Princeton University Press, 1999.

RASMUSSEN, J. Risk management in a dynamic society. Safety Science, v. 27, n. 2, p. 183-213, 1997.

REASON, J. Managing the risks of organizational accidents. Aldershot: Ashgate, 1997. . Safety paradoxes and safety culture. Injury Control and Safety Promotion. v. 7, n. 1, p. 3-14, 2000.

REASON, J.; HOBBS, A. Managing maintenance error: a practical guide. Hampshire: Ashgate, 2003.

SHRIVASTAVA, P. Bhopal: anatomy of a crisis. Cambridge: Ballinger Publishing Company, 1987.

VILELA, R. A. G.; IGUTI A. M.; ALMEIDA, I. M. Culpa da vítima: um modelo para perpetuar a impunidade nos acidentes do trabalho. Cad. Saúde Pública, Rio de Janeiro, v. 20, n. 2, p. 570-579, 2004.

WISNER, A. A inteligência no trabalho. São Paulo: Fundacentro, 1994.

WOODING, J.; LEVEINSTEIN, C. The point of production. Work environment in advanced idustrial societies. New York: The Guilford Press, 1999.

WOODS, D. D.; COOK, R. I. Nine steps to move forward from error. Cognition, Technology \& Work, n. 4, p. 137-144, 2002. 